\title{
(6) OPEN ACCESS \\ Riociguat for the treatment of pulmonary hypertension: Chinese subgroup analyses and comparison
}

\author{
Chen Wang, ${ }^{1}$ Zhi-Cheng Jing, ${ }^{2}$ Yi-Gao Huang, ${ }^{3}$ Da-Xin Zhou, ${ }^{4}$ Zhi-Hong Liu, ${ }^{5}$ \\ Christian Meier, ${ }^{6}$ Sylvia Nikkho, ${ }^{6}$ John Curram, ${ }^{7}$ Peng Zhang, ${ }^{8}$ Jian-Guo He ${ }^{5}$
}

\begin{abstract}
- Additional material is available. To view please visit the journal online (http://dx. doi.org/10.1136/heartasia2015-010712).
\end{abstract}

For numbered affiliations see end of article.

\section{Correspondence to} Dr Jian-Guo He, State Key Laboratory of Cardiovascular Disease, Fuwai Hospital, National Centre for Cardiovascular Diseases, Chinese Academy of Medical Sciences and Peking Union Medical College, No. 167, Beilishi Road, Xicheng District, Beijing 100037, China; hejianguofw@163.com

Received 27 November 2015 Revised 24 April 2016 Accepted 25 April 2016

\section{CrossMark}

To cite: Wang $C$, Jing $Z-C$ Huang Y-G, et al. Heart Asia 2016:8:74-82.

doi:10.1136/heartasia-2015010712

\section{ABSTRACT}

Objective PATENT-1 and CHEST-1 were pivotal, international phase III trials assessing riociguat for pulmonary arterial hypertension (PAH) and chronic thromboembolic pulmonary hypertension (CTEPH). Here we compare Chinese patients from these studies with the overall populations, and report the clinical effect and safety of riociguat in Chinese patients with $\mathrm{PAH}$ and CTEPH.

Methods PATENT-1 was a 12-week, randomised, double-blind, placebo-controlled trial of riociguat (maximum $2.5 \mathrm{mg}$ three times daily or $1.5 \mathrm{mg}$ three times daily (exploratory) in patients with PAH. CHEST-1 was a 16-week, randomised, double-blind, placebocontrolled trial of riociguat (maximum $2.5 \mathrm{mg}$ three times daily) in patients with inoperable CTEPH or persistent/recurrent pulmonary hypertension after pulmonary endarterectomy. The primary endpoint in each study was change from baseline to study end in $6 \mathrm{~min}$ walking distance (6MWD). Secondary endpoints included pulmonary vascular resistance (PVR), N-terminal prohormone of brain natriuretic peptide, WHO functional class (FC), and time to clinical worsening.

Results Chinese patients in PATENT-1 $(n=77)$ and CHEST-1 $(n=32)$ were younger and had better baseline 6MWD and WHO FC versus the overall population. Riociguat increased 6MWD versus placebo in Chinese patients in PATENT-1 and CHEST-1, with a greater increase observed in CHEST-1 (least-squares mean differences $+46 \mathrm{~m}$ and $+102 \mathrm{~m}$ in PATENT-1 and CHEST-1, respectively). Riociguat also improved several secondary endpoints in both studies, and was well tolerated.

Conclusions Chinese patients displayed differences in baseline characteristics versus the overall populations in PATENT-1 and CHEST-1. Riociguat improved 6MWD, PVR, WHO FC, and other clinical outcomes in Chinese patients with PAH or CTEPH.

Trial registration number PATENT-1: NCT00810693, Results; CHEST-1 NCT00855465, Results.

\section{INTRODUCTION}

Pulmonary arterial hypertension (PAH) and chronic thromboembolic pulmonary hypertension (CTEPH) are serious diseases that cause an increase in pulmonary vascular resistance (PVR) leading to right heart failure and eventually death. In PAH this results from remodelling of the small pulmonary arteries, whereas in CTEPH it is a consequence of obstructive unresolved thromboemboli in the pulmonary vasculature. ${ }^{1-3}$
PAH is primarily treated pharmacologically; available therapies include phosphodiesterase type 5 inhibitors, prostanoids, and endothelin receptor antagonists, ${ }^{1}$ with many further treatments in development. ${ }^{4}$ Despite this, the disease remains incurable and mortality rates remain high. ${ }^{5}$ Notably, there are fewer approved PAH-specific therapies available in China compared with the Western world, and their high cost has constrained their use. ${ }^{6}$

In contrast to $\mathrm{PAH}$, the recommended treatment for CTEPH is a surgical procedure-pulmonary endarterectomy (PEA) - which is potentially curative. ${ }^{13}$ However, although increasing, the number of specialist $\mathrm{PH}$ centres and expertise in PEA in China remain limited, and PEA is a relatively uncommon procedure. ${ }^{78}$ Furthermore, $20-40 \%$ of patients cannot undergo PEA or develop persistent/ recurrent pulmonary hypertension (PH) after surgery. ${ }^{9}$ While these patients are candidates for medical therapy, there is currently no approved pharmacological treatment for CTEPH in China, highlighting an important unmet need.

Riociguat is a soluble guanylate cyclase stimulator approved for the treatment of symptomatic PAH and inoperable or persistent/recurrent CTEPH in Europe, the USA, Canada, and Japan. Approval of riociguat for PAH and CTEPH was based on two international phase III studies in treatment-naïve or pre-treated patients with PAH (PATENT-1: Pulmonary Arterial Hypertension Soluble Guanylate Cyclase-Stimulator Trial 1) and patients with inoperable or persistent/recurrent CTEPH (CHEST-1: Chronic Thromboembolic Pulmonary Hypertension Soluble Guanylate Cyclase-Stimulator Trial 1). ${ }^{10}{ }^{11}$ Riociguat was well tolerated in both studies and significantly improved the primary endpoint of $6 \mathrm{~min}$ walking distance (6MWD) compared with placebo. Riociguat also improved a range of secondary endpoints, including change in PVR, change in serum concentrations of N-terminal prohormone of brain natriuretic peptide (NTproBNP), and change in WHO functional class (FC) ${ }^{10}{ }^{11}$ In PATENT-1, riociguat also significantly reduced the frequency of clinical worsening events compared with placebo. ${ }^{10}$

Most available data regarding the prevalence, diagnosis, treatment, and prognosis of $\mathrm{PH}$ are from North American and Western European populations; it is unclear whether these data are valid in Chinese populations. ${ }^{7}$ Here we report a subgroup analysis of PATENT-1 and CHEST- 1 evaluating the efficacy and safety of riociguat for Chinese patients 
with PAH and CTEPH, and investigating differences in baseline and clinical characteristics between Chinese patients and the overall cohort. The rationale for this analysis is that Chinese patients were among the largest sub-cohorts in the PATENT-1 and CHEST-1 studies, and their baseline characteristics were observed to differ from those of the overall study populations. It is therefore clinically relevant to analyse the efficacy and safety of riociguat in Chinese patients.

\section{METHODS}

\section{Patients, study design and outcome measures}

The PATENT-1 and CHEST-1 study methodologies have been reported previously; ${ }^{10} 11$ a summary of inclusion and exclusion criteria, study design, outcome measures, and statistical analyses is provided in the online supplementary information.

The studies were carried out in accordance with Good Clinical Practice Guidelines and the Declaration of Helsinki. The protocol was approved by the ethics committees of all participating centres and all patients gave their written informed consent. PATENT-1 and CHEST-1 are registered at Clinicaltrials.gov: PATENT-1: NCT00810693; CHEST-1: NCT00855465.

\section{Statistical analysis}

PATENT-1 and CHEST-1 were not designed to show statistically significant differences in subgroup populations; the subgroup data presented here were therefore analysed descriptively.

\section{RESULTS}

\section{Baseline characteristics in the Chinese subgroup}

Five centres in China participated in each study (table 1). Baseline characteristics of the Chinese patients randomly assigned to treatment in PATENT-1 and CHEST-1 were generally well balanced between the treatment groups (tables 2 and 3 ).

Of the 30 countries that participated in PATENT-1, China enrolled and randomised the most patients with PAH $(n=77)$, with Germany enrolling the second largest number $(n=73)$ (figure 1A). Among Chinese patients, idiopathic PAH was the most common diagnosis (69\%). Compared with the overall study population, Chinese patients were younger (mean \pm SD 38 \pm 14 vs $51 \pm 17$ years), more likely to be therapy naïve ( $88 \%$ vs $50 \%)$, had longer 6MWD (382 \pm 50 vs $363 \pm 69 \mathrm{~m})$, higher PVR $\left(1209 \pm 512\right.$ vs $811 \pm 473$ dynes $\left.\cdot \mathrm{s} \cdot \mathrm{cm}^{-5}\right)$, and were more likely to be in WHO FC I/II (65\% vs 45\%) (table 2). Four Chinese patients (5\%) withdrew from PATENT-1 before week

Table 1 Study centres and patients in China

\begin{tabular}{|c|c|c|c|c|c|}
\hline \multirow[b]{2}{*}{ Investigator and affiliation } & \multicolumn{5}{|c|}{ No. of patients } \\
\hline & $\begin{array}{l}\text { Total } \\
\text { enrolled }\end{array}$ & $\begin{array}{l}\text { Total } \\
\text { randomised }\end{array}$ & $\begin{array}{l}\text { Riociguat } \\
2.5 \text { mg-maximum } \\
\text { dose }\end{array}$ & $\begin{array}{l}\text { Riociguat } \\
1.5 \text { mg-maximum } \\
\text { dose }\end{array}$ & Placebo \\
\hline PATENT-1 & 83 & 77 & 43 & 10 & 24 \\
\hline $\begin{array}{l}\text { Professor Jian-Guo He (Lead investigator) } \\
\text { Cardiovascular Institute and Fuwai Hospital, Chinese Academy of Medical Sciences, } \\
\text { Beijing, China }\end{array}$ & 13 & 13 & 8 & 0 & 5 \\
\hline $\begin{array}{l}\text { Professor Zhi-Cheng Jing } \\
\text { Shanghai Pulmonary Hospital, Tongji University School of Medicine, Shanghai, China }\end{array}$ & 23 & 21 & 12 & 5 & 4 \\
\hline $\begin{array}{l}\text { Professor Da-Xin Zhou } \\
\text { Donghua Zhou, School of Medicine and Health Management, Tongji Medical College, } \\
\text { Huazhong University of Science and Technology, Wuhan, China }\end{array}$ & 12 & 12 & 5 & 2 & 5 \\
\hline $\begin{array}{l}\text { Professor Yi-Gao Huang } \\
\text { Institute of Vascular Medicine, Li Ka Shing Institute of Health Sciences, School of } \\
\text { Biomedical Sciences, Chinese University of Hong Kong, Hong Kong } \\
\text { Guangdong General Hospital and Guangdong Cardiovascular Institute, Guangzhou, } \\
\text { Guangdong, China }\end{array}$ & 16 & 13 & 8 & 2 & 3 \\
\hline $\begin{array}{l}\text { Professor Chen Wang } \\
\text { Beijing Institute of Respiratory Medicine, Beijing Chao-Yang Hospital, Capital Medical } \\
\text { University, Beijing, China } \\
\text { Department of Beijing Hospital, Ministry of Health, Beijing, China }\end{array}$ & 19 & 18 & 10 & 1 & 7 \\
\hline CHEST-1 & 58 & 32 & 21 & - & 11 \\
\hline $\begin{array}{l}\text { Associate Professor Zhi-Hong Liu } \\
\text { Centre for Pulmonary Vascular Diseases, Fuwai Hospital and Cardiovascular Institute, } \\
\text { Beijing, China }\end{array}$ & 7 & 4 & 3 & - & 1 \\
\hline $\begin{array}{l}\text { Professor Chen Wang } \\
\text { Beijing Institute of Respiratory Medicine, Beijing Chao-Yang Hospital, Capital Medical } \\
\text { University, Beijing, PR China } \\
\text { Department of Beijing Hospital, Ministry of Health, Beijing, China }\end{array}$ & 32 & 21 & 15 & - & 6 \\
\hline $\begin{array}{l}\text { Professor Zhao-Zhong Cheng } \\
\text { The Affiliated Hospital of Medical College of Qingdao, Shandong, China }\end{array}$ & 3 & 0 & 0 & - & 0 \\
\hline $\begin{array}{l}\text { Professor Zhi-Cheng Jing } \\
\text { Tongji University Affiliated Shanghai Pulmonary Hospital, Shanghai, China } \\
\text { Thrombosis and Vascular Medicine Centre, State Key Lab of Cardiovascular Disease, Fuwai } \\
\text { Hospital, Peking Union Medical College and Chinese Academy of Medical Sciences, } \\
\text { Beijing, China }\end{array}$ & 14 & 7 & 3 & - & 4 \\
\hline $\begin{array}{l}\text { Professor Lei Pan } \\
\text { Capital Medical University, Beijing, China } \\
\text { Beijing Municipal Key Laboratory of Clinical Epidemiology, Beijing, China }\end{array}$ & 2 & 0 & 0 & - & 0 \\
\hline
\end{tabular}


Table 2 Baseline demographic and clinical characteristics of the Chinese subgroup and overall study population in PATENT-1

\begin{tabular}{|c|c|c|c|c|c|c|c|c|}
\hline \multirow[b]{2}{*}{ Characteristic } & \multicolumn{4}{|c|}{ Chinese subgroup } & \multicolumn{4}{|c|}{ Overall study population } \\
\hline & $\begin{array}{l}\text { Placebo } \\
(n=24)\end{array}$ & $\begin{array}{l}\text { Riociguat } \\
2.5 \text { mg-maximum } \\
\text { group }(n=43)\end{array}$ & $\begin{array}{l}\text { Riociguat } \\
1.5 \mathrm{mg} \text {-maximum } \\
\text { group }(n=10)\end{array}$ & $\begin{array}{l}\text { Total } \\
(n=77)\end{array}$ & $\begin{array}{l}\text { Placebo } \\
(n=126)\end{array}$ & $\begin{array}{l}\text { Riociguat } \\
2.5 \text { mg-maximum } \\
\text { group }(n=254)\end{array}$ & $\begin{array}{l}\text { Riociguat } \\
1.5 \text { mg-maximum } \\
\text { group }(n=63)\end{array}$ & $\begin{array}{l}\text { Total } \\
(n=443)\end{array}$ \\
\hline Female, $\mathrm{n}(\%)$ & $18(75)$ & $34(79)$ & $9(90)$ & $61(79)$ & $98(78)$ & $203(80)$ & $49(78)$ & $350(79)$ \\
\hline Age, mean $\pm S D$ (years) & $41 \pm 16$ & $38 \pm 13$ & $33 \pm 14$ & $38 \pm 14$ & $51 \pm 17$ & $51 \pm 17$ & $49 \pm 16$ & $51 \pm 17$ \\
\hline \multicolumn{9}{|l|}{ Aetiology of PAH, $\mathrm{n}(\%)$} \\
\hline Idiopathic & $17(71)$ & $29(67)$ & $7(70)$ & $53(69)$ & $84(67)$ & $149(59)$ & $39(62)$ & $272(61)$ \\
\hline Familial & $1(4)$ & $4(9)$ & 0 & $5(7)$ & $1(1)$ & $7(3)$ & $1(2)$ & $9(2)$ \\
\hline Connective tissue disease & $2(8)$ & $6(14)$ & 0 & $8(10)$ & $25(20)$ & $71(28)$ & $15(24)$ & $111(25)$ \\
\hline Congenital heart disease & $3(13)$ & $3(7)$ & $3(30)$ & $9(12)$ & $12(10)$ & $15(6)$ & $8(13)$ & $35(8)$ \\
\hline Portopulmonary hypertension & 0 & $1(2)$ & 0 & $1(1)$ & $2(2)$ & $11(4)$ & 0 & $13(3)$ \\
\hline $\begin{array}{l}\text { Anorexigen or amphetamine } \\
\text { use }\end{array}$ & $1(4)$ & 0 & 0 & $1(1)$ & $2(2)$ & $1(<1)$ & 0 & $3(1)$ \\
\hline WHO FC I/II/III/IV, \% & $8 / 54 / 38 / 0$ & $2 / 67 / 30 / 0$ & $0 / 50 / 50 / 0$ & $4 / 61 / 35 / 0$ & $3 / 48 / 46 / 2^{*}$ & $2 / 43 / 55 /<1$ & $8 / 30 / 62 / 0$ & $3 / 42 / 54 / 1^{*}$ \\
\hline \multicolumn{9}{|c|}{ In receipt of additional PAH treatment at baseline, $\mathrm{n}(\%)$} \\
\hline No & $22(92)$ & $38(88)$ & $8(80)$ & $68(88)$ & $66(52)$ & $123(48)$ & $32(51)$ & $221(50)$ \\
\hline Yes & $2(8)$ & $5(12)$ & $2(20)$ & $9(12)$ & $60(48)$ & $131(52)$ & $31(49)$ & $222(50)$ \\
\hline $\begin{array}{l}\text { Endothelin receptor } \\
\text { antagonist }\end{array}$ & $1(4)$ & $1(2)$ & $2(20)$ & $4(5)$ & $54(43)$ & $113(45)$ & $27(43)$ & $194(44)$ \\
\hline Prostanoid & $1(4)$ & $4(9)$ & 0 & $5(7)$ & $7(6)$ & $20(8)$ & $4(6)$ & $31(7)$ \\
\hline $6 \mathrm{MWD}$, mean $\pm \mathrm{SD}(\mathrm{m})$ & $387 \pm 50$ & $382 \pm 51$ & $369 \pm 51$ & $382 \pm 50$ & $368 \pm 75$ & $361 \pm 68$ & $363 \pm 67$ & $363 \pm 69$ \\
\hline
\end{tabular}

${ }^{*}$ Data missing for one patient.

6MWD, 6 min walking distance; PAH, pulmonary arterial hypertension; WHO FC, WHO functional class (ranges from I to IV, with higher numbers indicating greater functional limitations).

12 (figure 1A) compared with 38 patients (9\%) in the overall study population.

Of the 26 countries that participated in CHEST-1, China enrolled the second highest number of patients with CTEPH $(n=32)$ (figure 1B), with Germany enrolling the highest number $(n=57)$. Compared with the overall study population, more Chinese patients had inoperable CTEPH (91\% vs 72\%), and more patients were in WHO FC I/II (59\% vs 32\%) (table 3). Additionally, Chinese patients were younger (mean \pm SD $49 \pm 11$ vs $59 \pm 14$ years) and had longer 6MWD (371 \pm 67 vs 347 $\pm 80 \mathrm{~m})$ and higher PVR $\left(1062 \pm 439\right.$ vs $\left.787 \pm 420 \mathrm{dynes} / \mathrm{s} / \mathrm{cm}^{5}\right)$ than the overall population. Two Chinese patients (6\%) withdrew from CHEST-1 before week 16 (figure 1B) compared with 18 patients $(7 \%)$ in the overall study population.

Although PATENT-1 and CHEST-1 investigated two distinct types of $\mathrm{PH}$ (WHO groups 1 and 4), a comparison of baseline demographic characteristics between the studies showed similarities between the Chinese populations; however, there was a higher proportion of women in PATENT-1 than in CHEST-1 (79\% vs 69\%), and patients in PATENT-1 were younger than patients in CHEST-1 (mean \pm SD $38 \pm 14$ vs $49 \pm 11$ years; tables 2 and 3 ).

\section{Efficacy and safety of riociguat in the Chinese subgroup Primary endpoint}

At the end of PATENT-1, the mean 6MWD change from baseline in Chinese patients was $+31 \mathrm{~m}$ in the $2.5 \mathrm{mg}$-maximum group $(n=43)$ and $-16 \mathrm{~m}$ in the placebo group $(n=24)$ (least-squares (LS) mean difference, $+46 \mathrm{~m}$; 95\% CI 5 to $87 \mathrm{~m}$; table 4; figure 2A).

At the end of CHEST-1, the mean change from baseline in $6 \mathrm{MWD}$ in Chinese patients was $+51 \mathrm{~m}$ in the riociguat

Table 3 Baseline demographic and clinical characteristics of the Chinese subgroup and overall study population in CHEST-1

\begin{tabular}{|c|c|c|c|c|c|c|}
\hline \multirow[b]{2}{*}{ Characteristic } & \multicolumn{3}{|c|}{ Chinese subgroup } & \multicolumn{3}{|c|}{ Overall study population } \\
\hline & $\begin{array}{l}\text { Placebo } \\
(n=11)\end{array}$ & $\begin{array}{l}\text { Riociguat } \\
2.5 \mathrm{mg} \text {-maximum } \\
\text { group }(\mathrm{n}=21)\end{array}$ & $\begin{array}{l}\text { Total } \\
(\mathrm{n}=32)\end{array}$ & $\begin{array}{l}\text { Placebo } \\
(n=88)\end{array}$ & $\begin{array}{l}\text { Riociguat } \\
2.5 \text { mg-maximum } \\
\text { group }(n=173)\end{array}$ & $\begin{array}{l}\text { Total } \\
(n=261)\end{array}$ \\
\hline Female, $n(\%)$ & $8(73)$ & $14(67)$ & $22(69)$ & $54(61)$ & $118(68)$ & $172(66)$ \\
\hline Age, mean $\pm S D$ (years) & $52 \pm 13$ & $47 \pm 10$ & $49 \pm 11$ & $59 \pm 13$ & $59 \pm 14$ & $59 \pm 14$ \\
\hline WHO FC I/II/IIIIIV, \% & $0 / 55 / 45 / 0$ & $10 / 52 / 38 / 0$ & $6 / 53 / 41 / 0$ & $0 / 28 / 68 / 2^{*}$ & $2 / 32 / 62 / 5$ & $1 / 31 / 64 / 4^{*}$ \\
\hline \multicolumn{7}{|l|}{ CTEPH, n (\%) } \\
\hline Inoperable & $10(91)$ & $19(91)$ & $29(91)$ & $68(77)$ & $121(70)$ & $189(72)$ \\
\hline Postoperative & $1(9)$ & $2(10)$ & $3(9)$ & $20(23)$ & $52(30)$ & $72(28)$ \\
\hline $6 \mathrm{MWD}$, mean $\pm \mathrm{SD}(\mathrm{m})$ & $364 \pm 85$ & $375 \pm 57$ & $371 \pm 67$ & $356 \pm 75$ & $342 \pm 82$ & $347 \pm 80$ \\
\hline
\end{tabular}


Figure 1 Disposition of Chinese patients in PATENT-1 (A) and CHEST-1 (B). CTEPH, chronic thromboembolic pulmonary hypertension; PAH, pulmonary arterial hypertension.
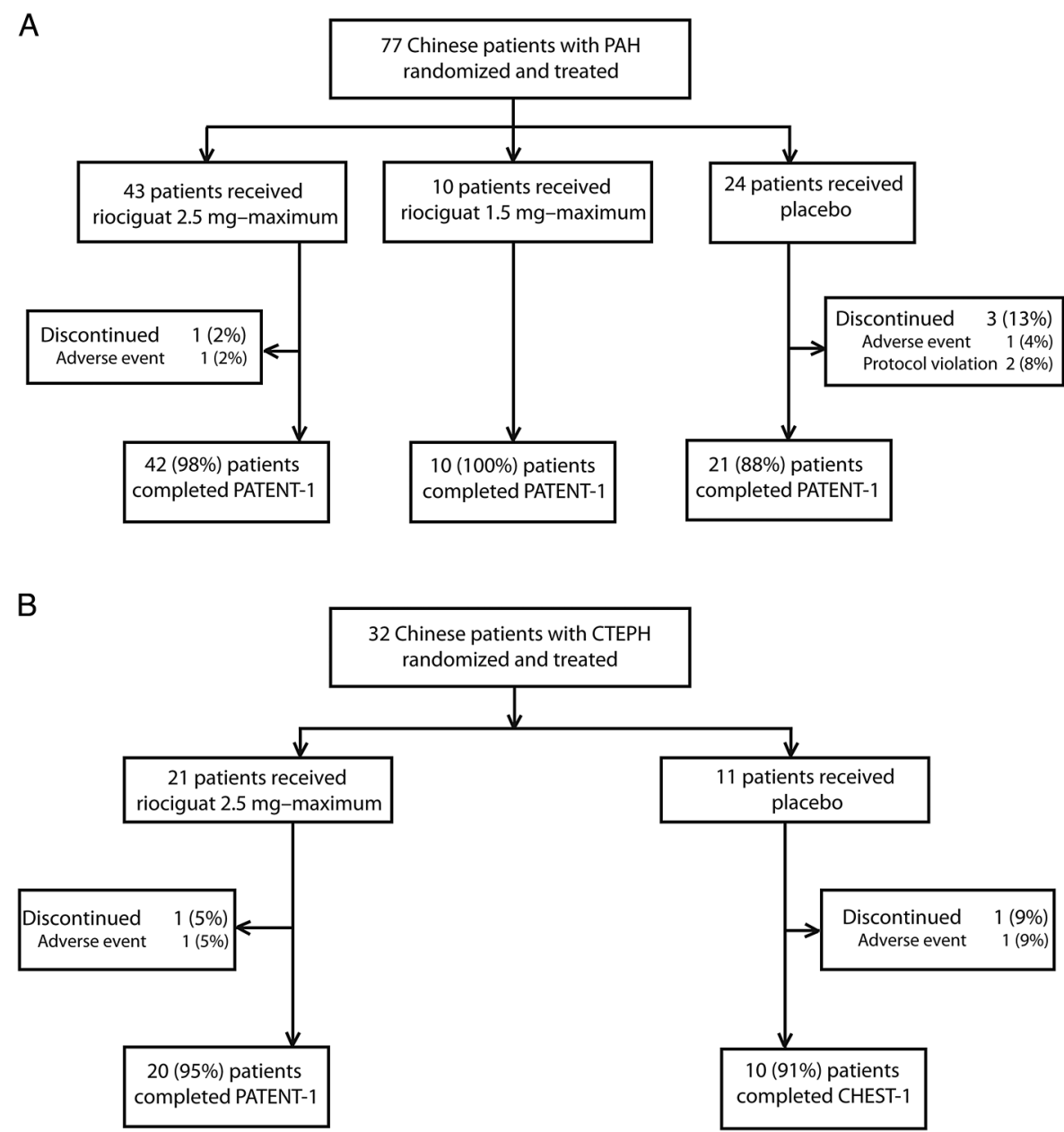

2.5 mg-maximum group $(\mathrm{n}=21)$ and $-48 \mathrm{~m}$ in the placebo group $(n=11)$ (LS mean difference, $+102 \mathrm{~m}$; 95\% CI 39 to $165 \mathrm{~m}$; table 4; figure 2B). One patient in the placebo group died, leading to a worst-case imputation $(0 \mathrm{~m})$, which contributed to the decrease in 6MWD observed in the placebo group, owing to low patient numbers in this group. However, even without this imputation, the LS mean difference is consistent with the treatment effect in the overall population.

The improvement in mean $6 \mathrm{MWD}$ with riociguat compared with placebo appeared to be higher in Chinese patients with CTEPH from CHEST-1 compared with Chinese patients with PAH from PATENT-1 (LS mean difference, +102 vs $+46 \mathrm{~m}$; table 4). This may be due in part to the longer treatment duration in CHEST-1 compared with PATENT-1 (16 vs 12 weeks). However, the difference may also be due to the relatively small sample size of the Chinese subgroups and baseline differences compared with the overall study populations.

\section{Secondary endpoints}

Riociguat improved several secondary endpoints compared with placebo in Chinese patients with PAH in PATENT-1, including PVR, NT-proBNP concentrations, and WHO FC (table 4). After 12 weeks of treatment, WHO FC had improved or stabilised in $97 \%$ of patients receiving riociguat compared with $75 \%$ of patients receiving placebo. There were also small improvements in favour of riociguat treatment in Borg dyspnoea, EuroQol Group 5-Dimension Self-Report Questionnaire (EQ-5D), and Living with Pulmonary Hypertension (LPH) scores (table 4). In the PATENT-1 Chinese cohort there was one clinical worsening event (death) in both the riociguat and placebo groups (table 5).

In CHEST-1, riociguat improved PVR, NT-proBNP values, and WHO FC compared with placebo in Chinese patients with CTEPH (table 4). After 16 weeks of treatment, WHO FC had improved or stabilised in $95 \%$ of patients receiving riociguat compared with $91 \%$ of patients receiving placebo. Riociguat was also associated with small improvements in Borg dyspnoea, EQ-5D, and LPH scores (table 4). One clinical worsening event (death) was reported in the placebo group in the CHEST-1 Chinese cohort (table 5).

Similar to the primary endpoint, improvements in secondary endpoints with riociguat compared with placebo appeared to be consistent between the PATENT-1 and CHEST-1 studies (table 4), although the relatively small sample size of the Chinese subgroups compared with the overall study populations should be taken into consideration when interpreting these results.

\section{Adverse events}

The most common adverse events (AEs) in Chinese patients with PAH during the PATENT-1 study period are shown in table 5. Consistent with the overall population, hypotension was more common in Chinese patients in the riociguat $2.5 \mathrm{mg}$ maximum group (14\%) compared with the $1.5 \mathrm{mg}$-maximum and placebo groups (10\% and $0 \%$, respectively). There were six serious AEs (SAEs) in the Chinese cohort of PATENT-1: two in the $2.5 \mathrm{mg}$-maximum group (one case each of intra-abdominal haemorrhage and haemoptysis) and four in the placebo group 
Table 4 Change from baseline to the end of week 12 in PATENT-1 and week 16 in CHEST-1 in primary and secondary endpoints in the Chinese patient populations

\begin{tabular}{|c|c|c|c|c|c|c|c|}
\hline & \multicolumn{3}{|l|}{ Placebo } & \multicolumn{3}{|c|}{$\begin{array}{l}\text { Riociguat } \\
2.5 \mathrm{mg} \text {-maximum group }\end{array}$} & \multirow[b]{2}{*}{$\begin{array}{l}\text { LS mean difference } \\
(95 \% \mathrm{Cl})\end{array}$} \\
\hline & $\begin{array}{l}\text { No. of } \\
\text { patients }\end{array}$ & Baseline & Change & $\begin{array}{l}\text { No. of } \\
\text { patients }\end{array}$ & Baseline & Change & \\
\hline \multicolumn{8}{|l|}{ PATENT-1 } \\
\hline \multicolumn{8}{|l|}{ Primary endpoint } \\
\hline 6MWD (m) & 24 & $387 \pm 50$ & $-16 \pm 73$ & 43 & $382 \pm 51$ & $31 \pm 83$ & 46 (5 to 87$)$ \\
\hline \multicolumn{8}{|l|}{ Secondary endpoints } \\
\hline PVR (dynes $/ \mathrm{s} / \mathrm{cm}^{5}$ ) & 21 & $1154 \pm 511$ & $83 \pm 480$ & 41 & $1232 \pm 542$ & $-379 \pm 333$ & $-436(-623$ to -249$)$ \\
\hline NT-proBNP (pg/mL) & 21 & $1328 \pm 1914$ & $127 \pm 796$ & 43 & $1152 \pm 1162$ & $-571 \pm 866$ & $-761(-1085$ to -436$)$ \\
\hline WHO FC, n (\%) & 24 & $\begin{array}{l}\text { I: } 2(8 \%) \\
\text { II: } 13(54 \%) \\
\text { III: } 9(38 \%) \\
\text { IV: } 0\end{array}$ & $\begin{array}{l}\text { Improved: } 6(25 \%) \\
\text { Stabilised: } 12(50 \%) \\
\text { Worsened: } 6(25 \%)\end{array}$ & 43 & $\begin{array}{l}\text { I: } 1(2 \%) \\
\text { II: } 29(67 \%) \\
\text { III: } 13(30 \%) \\
\text { IV: } 0\end{array}$ & $\begin{array}{l}\text { Improved: } 7(16 \%) \\
\text { Stabilised: } 35(81 \%) \\
\text { Worsened: } 1(2 \%)\end{array}$ & - \\
\hline Borg dyspnoea score* & 24 & $3.2 \pm 1.7$ & $0.2 \pm 2.1$ & 43 & $2.9 \pm 1.5$ & $-0.4 \pm 1.5$ & - \\
\hline EQ-5D score & 23 & $0.7 \pm 0.1$ & $-0.06 \pm 0.3$ & 43 & $0.7 \pm 0.3$ & $0.06 \pm 0.2$ & $0.1(-0.01$ to 0.2$)$ \\
\hline LPH score & 24 & $50 \pm 24$ & $1.5 \pm 16$ & 43 & $48 \pm 25$ & $-9 \pm 18$ & $-11(-19$ to -3$)$ \\
\hline \multicolumn{8}{|l|}{ CHEST-1 } \\
\hline \multicolumn{8}{|l|}{ Primary endpoint } \\
\hline 6MWD (m) & 11 & $364 \pm 85$ & $-48 \pm 122$ & 21 & $375 \pm 57$ & $51 \pm 55$ & 102 (39 to 165) \\
\hline \multicolumn{8}{|l|}{ Secondary endpoints } \\
\hline PVR (dynes/s/cm ${ }^{5}$ & 10 & $1037 \pm 584$ & $95 \pm 358$ & 18 & $1075 \pm 354$ & $-249 \pm 262$ & $-338(-577$ to -99$)$ \\
\hline NT-proBNP (pg/mL) & 11 & $2022 \pm 2492$ & $510 \pm 839$ & 21 & $1601 \pm 1151$ & $-538 \pm 1107$ & $-1042(-1841$ to -242$)$ \\
\hline WHO FC, n (\%) & 11 & $\begin{array}{l}\text { I: } 0 \\
\text { II: } 6(55 \%) \\
\text { III: } 5(45 \%) \\
\text { IV: } 0\end{array}$ & $\begin{array}{l}\text { Improved: } 1(9 \%) \\
\text { Stabilised: } 9(82 \%) \\
\text { Worsened: } 1(9 \%)\end{array}$ & 21 & $\begin{array}{l}\text { I: } 2(10 \%) \\
\text { II: } 11(52 \%) \\
\text { III: } 8(38 \%) \\
\text { IV: } 0\end{array}$ & $\begin{array}{l}\text { Improved: } 8(38 \%) \\
\text { Stabilised: } 12(57 \%) \\
\text { Worsened: } 1(5 \%)\end{array}$ & - \\
\hline Borg dyspnoea score* & 11 & $4.5 \pm 2.5$ & $-0.5 \pm 3.6$ & 21 & $3.5 \pm 2.0$ & $-1.2 \pm 2.3$ & - \\
\hline EQ-5D score & 11 & $0.6 \pm 0.1$ & $-0.1 \pm 0.4$ & 21 & $0.5 \pm 0.3$ & $0.2 \pm 0.2$ & $0.3(0.1$ to 0.5$)$ \\
\hline LPH score & 11 & $72 \pm 17$ & $-5 \pm 21$ & 21 & $59 \pm 22$ & $-19 \pm 21$ & $-21(-35$ to -6$)$ \\
\hline
\end{tabular}

Mean \pm SD values are presented unless otherwise stated.

*Borg dyspnoea scale ranges from 0 to 10 , with 0 representing no dyspnoea and 10 representing maximal dyspnoea.

6MWD, 6 min walking distance; EQ-5D, EuroQol Group 5-Dimension Self-Report Questionnaire (scores range from - 0.6 to 1.0, with higher scores indicating a better quality of life); LPH, Living with Pulmonary Hypertension questionnaire (an adaptation of the Minnesota Living with Heart Failure Questionnaire; scores range from 0 to 105 , with higher scores indicating worse quality of life); LS, least-squares; NT-proBNP, N-terminal prohormone of brain natriuretic peptide; PVR, pulmonary vascular resistance; WHO FC, WHO functional class (ranges from I to IV, with higher numbers indicating greater functional limitations).

(one case each of infectious diarrhoea, infectious enterocolitis, circulatory collapse, and respiratory failure). None of the SAEs was considered to be study-drug related. Two patients (3\%) discontinued treatment due to SAEs, which were severe and led to death. These deaths occurred in one patient $(2 \%)$ in the 2.5 mg-maximum group (haemoptysis) and one patient (4\%) in the placebo group (circulatory collapse and respiratory failure); neither was considered by the investigator to be related to the study drug. The proportion of discontinuations due to SAEs in Chinese patients was similar to that seen in the overall study population (3\% and 4\%, respectively).

The AEs that occurred most frequently in Chinese patients with CTEPH during the CHEST-1 study period are shown in table 5. No cases of hypotension were reported in Chinese patients with CTEPH. SAEs occurred in two patients (10\%) in the riociguat group (one case each of anal abscess and overdose of study drug) and one patient (9\%) in the placebo group (cardiac arrest), which led to death. None of the SAEs was considered to be study-drug related. One patient $(5 \%)$ in the riociguat group discontinued the study drug due to an AE (overdose of study drug) which resolved. By comparison, seven patients $(3 \%)$ in the overall study population discontinued due to AEs (five in the riociguat group and two in the placebo group), and a total of six patients (2\%) discontinued due to SAEs.

\section{DISCUSSION}

The PATENT-1 and CHEST-1 studies demonstrated that the soluble guanylate cyclase stimulator riociguat significantly improved a range of clinically relevant endpoints in a worldwide population of patients with $\mathrm{PAH}$, who were either treatment naïve or pre-treated with endothelin receptor antagonists or prostanoids, ${ }^{10}$ and patients with CTEPH, who were either ineligible for surgery or who had persistent/recurrent $\mathrm{PH}$ after undergoing PEA. ${ }^{11}$ Here we report the findings from the subgroups of patients with PAH or CTEPH from China, which was one of the highest contributors of patients to both studies. Registries from China have shown that the demographics and patient characteristics of the Chinese population are similar to those of patients in early studies from the US National Institutes of Health Registry; however, Chinese patients with PAH tended to be younger, and had higher baseline PVR index and mean pulmonary arterial pressure, than patients with $\mathrm{PAH}$ in more recent European and North American registries. ${ }^{12}$ The characteristics of the Chinese populations in PATENT-1 and CHEST-1 were similar to those of patients with $\mathrm{PH}$ from 31 clinical centres across China. ${ }^{13}$

Patients in the Chinese population were younger and had better functional condition at baseline compared with the overall population, despite having higher baseline PVR. This 
Figure 2 Mean change from baseline in 6MWD in (A) Chinese patients with PAH in PATENT-1 and (B) Chinese patients with CTEPH in CHEST-1. Mean $( \pm$ SEM) changes from baseline in 6MWD are shown for the modified intention-to-treat Chinese population without imputation of missing values, with the imputed values also provided at week 12 (PATENT-1) and week 16 (CHEST-1). The number of patients at each time point is indicated below the graph. Missing data were imputed at week 12/16 according to the last observation carried forward, except in cases of death or clinical worsening without a termination visit, where the worst value $(0 \mathrm{~m})$ was imputed. 6MWD, 6 min walking distance; $\mathrm{CTEPH}$, chronic thromboembolic pulmonary hypertension; PAH, pulmonary arterial hypertension.
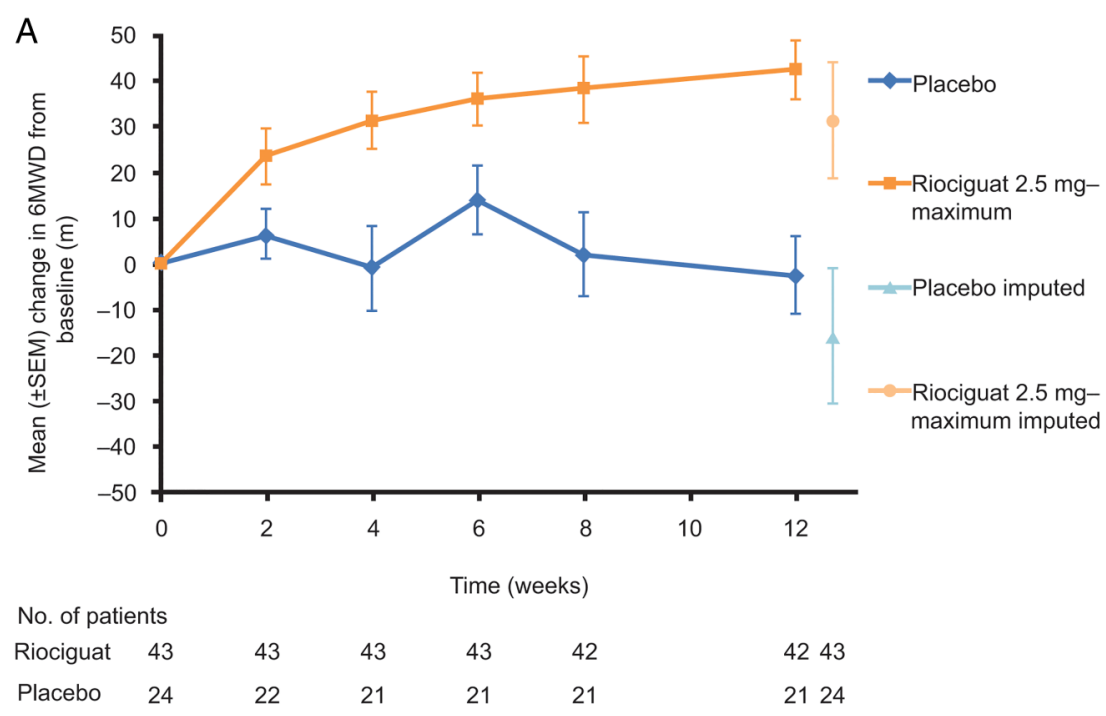

B

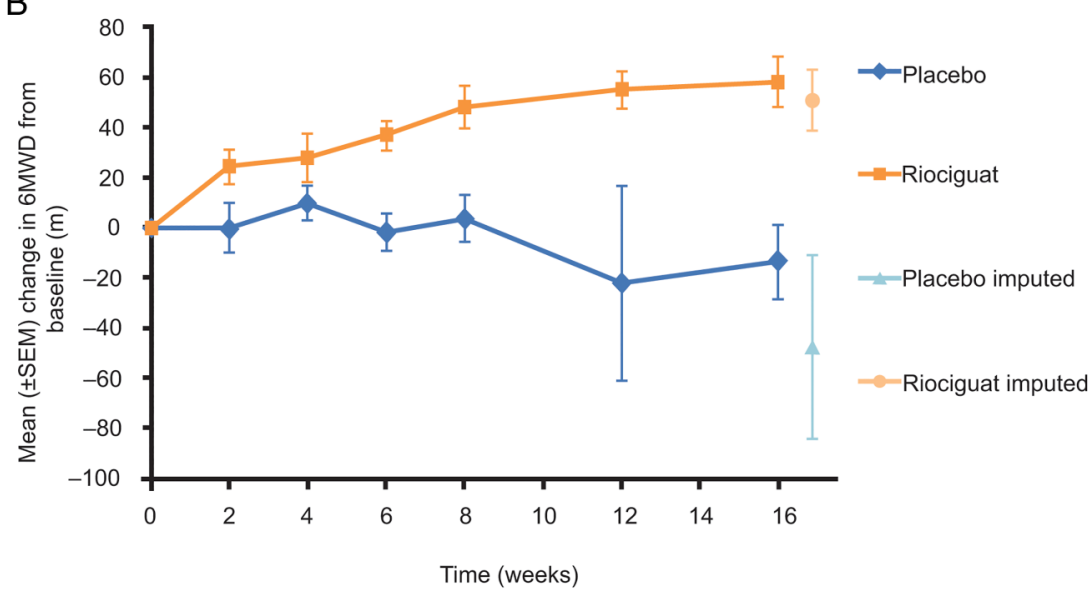

No. of patients

$\begin{array}{llllllll}\text { Riociguat } & 21 & 21 & 21 & 20 & 20 & 20 & 2021 \\ \text { Placebo } & 11 & 11 & 10 & 10 & 10 & 10 & 1011\end{array}$

may be because WHO FC is determined according to the subjective reporting of symptoms by the patient, with 6MWD also affected by subjective factors such as patient motivation. We propose that because Chinese patients in PATENT-1 and CHEST-1 were younger and primarily from rural areas, they would have had greater exposure to manual labour before the onset of their disease and during its early stages. Therefore, they may have had better tolerance to exertional dyspnoea and better pulmonary and cardiac functional adaptability than patients with no history of long-term physical work, resulting in better WHO FC and 6MWD despite higher PVR.

Chinese patients with PAH in PATENT-1 were more likely to be therapy naïve than patients in the overall study population, which may reflect the limited availability of approved therapies for PAH in China and cost constraints on their use. ${ }^{6}$ This limited access to treatment outside of a clinical trial setting may account for the higher baseline PVR values in the Chinese subgroup compared with the overall population. Furthermore, such limited access may extend to treatment with riociguat.

Chinese patients in CHEST-1 were more likely to have inoperable CTEPH than patients in the overall study population. This may be due to a lower number of patients undergoing PEA in China, decreasing the likelihood of recruiting patients with postoperative CTEPH. The relative lack of access to PEA in
China may lead to the use of riociguat in patients who are potentially operable. ${ }^{78}$ However, it should be stressed that riociguat is only indicated for patients with inoperable or persistent/recurrent CTEPH, and that PEA remains the gold standard treatment as it is potentially curative. ${ }^{1}$

Improvements in 6MWD were observed in the Chinese population of PATENT-1. The treatment effect of riociguat on 6MWD $(+46 \mathrm{~m})$ appeared to be greater than that previously reported in the overall study population $(+36 \mathrm{~m}) .{ }^{10}{ }^{11}$ The high number of treatment-naïve Chinese patients in PATENT-1, as well as their younger age and longer 6MWD at baseline, may have contributed to this observation. While direct comparison between the results of different clinical trials requires caution, the effect of riociguat on 6MWD in Chinese patients appeared to be in a similar range as observed with other PAH treatments in North American or Western European populations (16$59 \mathrm{~m}),{ }^{14-19}$ and Chinese populations $(17-75 \mathrm{~m}),{ }^{20-25}$ and was above the threshold reported to represent a clinically relevant change $(33-42 \mathrm{~m}) .^{26} 27$

In CHEST-1, the change from baseline in 6MWD with riociguat treatment appeared to be greater in Chinese patients $(+51 \mathrm{~m})$ relative to that in the overall study population $(+39 \mathrm{~m}) .{ }^{10} 11$ This may be related to the high numbers of inoperable Chinese patients in CHEST-1. However, the relatively 
Table 5 Clinical worsening events and AEs in Chinese patients in PATENT-1 and CHEST-1

\begin{tabular}{|c|c|c|c|c|c|}
\hline \multirow[b]{2}{*}{ Event, $\mathrm{n}(\%)$} & \multicolumn{3}{|l|}{ PATENT-1 } & \multicolumn{2}{|l|}{ CHEST-1 } \\
\hline & Placebo $(n=24)$ & $\begin{array}{l}\text { Riociguat } \\
2.5 \mathrm{mg} \text {-maximum } \\
\text { group }(\mathrm{n}=43)\end{array}$ & $\begin{array}{l}\text { Riociguat } \\
1.5 \mathrm{mg} \text {-maximum } \\
\text { group }(\mathrm{n}=10)\end{array}$ & Placebo $(n=11)$ & $\begin{array}{l}\text { Riociguat } \\
2.5 \mathrm{mg} \text {-maximum } \\
\text { group }(\mathrm{n}=21)\end{array}$ \\
\hline \multicolumn{6}{|l|}{ Clinical worsening } \\
\hline All events & $1(4)$ & $1(2)$ & 0 & $1(9)$ & 0 \\
\hline Death & $1(4)$ & $1(2)$ & 0 & 1 (9) & 0 \\
\hline \multicolumn{6}{|l|}{ AEs } \\
\hline Any & $18(75)$ & $33(77)$ & $9(90)$ & $11(100)$ & $21(100)$ \\
\hline Peripheral oedema & $3(13)$ & $5(12)$ & 0 & $3(27)$ & $2(10)$ \\
\hline Headache & $1(4)$ & $6(14)$ & $3(30)$ & 0 & $5(24)$ \\
\hline Hypotension & 0 & $6(14)$ & $1(10)$ & 0 & 0 \\
\hline Dizziness & $1(4)$ & $4(9)$ & $1(10)$ & 0 & $7(33)$ \\
\hline Upper respiratory tract infection & $3(13)$ & $1(2)$ & 0 & $2(18)$ & $2(10)$ \\
\hline Chest discomfort & $4(17)$ & $1(2)$ & 0 & 0 & $2(10)$ \\
\hline Cough & $2(8)$ & $2(5)$ & $1(10)$ & $3(27)$ & $1(5)$ \\
\hline Nausea & $2(8)$ & $1(2)$ & $1(10)$ & 1 (9) & $1(5)$ \\
\hline Gastro-oesophageal reflux disease & $2(8)$ & $2(5)$ & 0 & 0 & $2(10)$ \\
\hline Abdominal discomfort & 0 & $2(5)$ & 0 & 0 & $5(24)$ \\
\hline Dyspepsia & 0 & $2(5)$ & $2(20)$ & 0 & $2(10)$ \\
\hline Erythema & 0 & 0 & $2(20)$ & $2(18)$ & 0 \\
\hline Palpitations & 0 & $2(5)$ & $1(10)$ & 0 & $2(10)$ \\
\hline Nasopharyngitis & $3(13)$ & $1(2)$ & $1(10)$ & 0 & 0 \\
\hline Presyncope & 0 & 0 & $1(10)$ & 0 & 0 \\
\hline Constipation & $1(4)$ & 0 & $1(10)$ & 0 & 0 \\
\hline Dysphagia & 0 & $1(2)$ & $1(10)$ & 0 & 0 \\
\hline Prolonged activated partial thromboplastin time & $3(13)$ & $3(7)$ & 0 & $2(18)$ & $8(38)$ \\
\hline Increased blood glucose & 0 & 0 & $1(10)$ & 0 & 0 \\
\hline Decreased potassium & $1(4)$ & $2(5)$ & $1(10)$ & $1(9)$ & 0 \\
\hline Increased INR & $3(13)$ & $4(9)$ & 0 & 1 (9) & $7(33)$ \\
\hline Decreased WBC count & 0 & 0 & 0 & 1 (9) & $2(10)$ \\
\hline Hypokalaemia & 0 & $1(2)$ & $3(30)$ & 0 & 0 \\
\hline Dyspnoea & $1(4)$ & $1(2)$ & $1(10)$ & 0 & 0 \\
\hline Productive cough & 1 (4) & 0 & 1 (10) & 0 & 1 (5) \\
\hline
\end{tabular}

The AEs listed here are those that occurred in $\geq 10 \%$ of the patients in any group during the treatment period.

$A E$, adverse event; INR, international normalised ratio; WBC, white blood cell.

small sample size of the Chinese sub-cohort, and the potential impact of a worst-case imputation $(0 \mathrm{~m})$ for a Chinese patient who died in the placebo group, should be taken into consideration when interpreting these results. The improvement in exercise capacity should be considered an important result of CHEST-1, both in the overall population and in this subanalysis, as it has not been previously shown in relevant clinical studies. ${ }^{28}$

In PATENT-1 and CHEST-1, Chinese patients appeared to benefit from improvements in PVR and NT-proBNP at least as much as patients in the overall population. ${ }^{10}{ }^{11}$ In PATENT-1, the improvements in PVR and NT-proBNP were numerically greater in Chinese patients compared with the overall population. ${ }^{10}$ In CHEST-1, the effect of riociguat on PVR was similar between Chinese patients and the overall population, whereas NT-proBNP concentrations improved to a greater extent. ${ }^{11}$ However, since these were exploratory post-hoc subgroup analyses, these data should be interpreted with caution. Furthermore, the greater improvement in PVR among Chinese patients in PATENT-1 may have been driven in part by higher baseline PVR in the Chinese subgroup.

There were too few clinical worsening events $(n=2)$ in the Chinese population in PATENT-1 to detect a difference between the riociguat and placebo groups, although a significant difference was seen in the overall study population. ${ }^{10}$ However, the fact that riociguat decreased the proportion of patients experiencing a deterioration in WHO FC supports the clinical effect of riociguat.

The safety and tolerability of riociguat in Chinese patients with PAH and CTEPH were comparable to the overall study populations, with no new safety signals observed. Two serious bleeding events were reported in Chinese patients receiving riociguat in PATENT-1, including one case of haemoptysis (which was fatal) and one case of intra-abdominal haemorrhage (which resolved; this patient subsequently entered the PATENT-2 extension). Neither was considered to be study-drug related by the investigator. As for the overall population, prescribers should regularly assess the risk of pulmonary bleeding in Chinese patients receiving riociguat. Furthermore, although no specific safety signals were observed in the Chinese population, the dose of riociguat should still be carefully adjusted to the optimum level based on systolic blood pressure and signs and symptoms of hypotension, as described previously. ${ }^{10} 11$

Several studies have investigated medical therapies in Chinese patients with PAH, including bosentan and sildenafil. ${ }^{20} 23-25$ However, these studies were all open-label and uncontrolled, making comparisons with PATENT-1 difficult. To our 
knowledge there have been no studies of targeted therapies in Chinese patients with CTEPH.

The main limitation of these subgroup analyses is that the PATENT-1 and CHEST-1 studies were not designed to show statistically significant differences in the subgroups. The data presented here should therefore be considered exploratory.

In conclusion, Chinese patients with PAH or CTEPH showed some differences in baseline demographic characteristics compared with the international populations in PATENT-1 and CHEST-1, although improvements in clinical outcomes with riociguat were generally reflective of the overall clinical results of both studies. Riociguat was well tolerated in Chinese patients, and the AE profile was similar to that observed in the overall populations. These findings suggest that riociguat can provide clinically meaningful improvements in Chinese patients with $\mathrm{PAH}$ and $\mathrm{CTEPH}$.

\section{Key messages}

What is already known about this subject?

Pulmonary arterial hypertension (PAH) and chronic

thromboembolic pulmonary hypertension (CTEPH) are chronic and progressive conditions that can lead to right heart failure. Most available data regarding the treatment of PAH and CTEPH are from North American and Western European populations, but whether these data are also valid in Chinese patients remains controversial.

\section{What does this study add?}

This subgroup analysis of the phase III PATENT-1 and CHEST-1 studies demonstrates that the soluble guanylate cyclase stimulator riociguat was well tolerated in Chinese patients with PAH and CTEPH, and significantly improved a range of primary and secondary efficacy endpoints versus placebo. The safety and efficacy profile of riociguat was comparable with that observed in the overall patient populations.

\section{How might this impact on clinical practice?}

These data suggest that riociguat is a well-tolerated and effective treatment for Chinese patients with PAH and CTEPH.

\section{Author affiliations}

'Department of Respiratory Medicine, Beijing Institute of Respiratory Medicine, Beijing Chaoyang Hospital, Capital Medical University, Beijing Key Laboratory of Respiratory and Pulmonary Circulation Disorders, Beijing, China

${ }^{2}$ State Key Laboratory of Cardiovascular Disease, Fuwai Hospital, Peking Union Medical College and Chinese Academy of Medical Sciences, Beijing, China ${ }^{3}$ Department of Cardiology, Guangdong General Hospital and Guangdong Cardiovascular Institute, Guangzhou, Guangdong, China

${ }^{4}$ Department of Cardiology, Zhongshan Hospital, Fudan University, Shanghai Institute of Cardiovascular Diseases, Shanghai, China

${ }^{5}$ State Key Laboratory of Cardiovascular Diseases, Fuwai Hospital, National Centre for Cardiovascular Diseases Chinese Academy of Medical Sciences and Peking Union Medical College, Beijing, China

${ }^{6}$ Global Clinical Development, Bayer Pharma AG, Berlin, Germany

${ }^{7}$ Global Development, Bayer plc, Newbury, UK

${ }^{8}$ Medical Affairs, Bayer Healthcare, Beijing, China

Contributors All authors contributed to the conception and design of the study, the analysis and interpretation of the data, and the drafting, critical review and approval of the final manuscript.

Funding The PATENT-1 and CHEST-1 studies were supported by Bayer Pharma AG (Berlin, Germany). Editorial assistance was provided by Adelphi Communications Ltd
(Bollington, UK), sponsored by Bayer Pharma AG. The study manager was Diana Klein (Bayer Pharma AG).

Competing interests CW, Y-GH, D-XZ, Z-HL and J-GH have been board or advisory committee members for Bayer Pharma AG. Z-CJ has received personal fees from Actelion, Bayer Pharma AG, Pfizer and United Therapeutics. CM, SN, JC and $\mathrm{PZ}$ are full-time employees of Bayer Pharma AG.

Ethics approval The institutional review board at each participating centre approved the protocol.

Patient consent obtained.

Provenance and peer review Not commissioned; externally peer reviewed.

Clinical trial acronyms PATENT-1: Pulmonary Arterial hyperTENsion sGC-stimulator Trial-1. CHEST-1: CHronic thromboEmbolic pulmonary hypertension sGC-Stimulator Trial-1.

Open Access This is an Open Access article distributed in accordance with the Creative Commons Attribution Non Commercial (CC BY-NC 4.0) license, which permits others to distribute, remix, adapt, build upon this work non-commercially, and license their derivative works on different terms, provided the original work is properly cited and the use is non-commercial. See: http://creativecommons.org/ licenses/by-nc/4.0/

\section{REFERENCES}

1 Galiè N, Humbert M, Vachiery JL, et al. 2015 ESC/ERS Guidelines for the diagnosis and treatment of pulmonary hypertension: The Joint Task Force for the Diagnosis and Treatment of Pulmonary Hypertension of the European Society of Cardiology (ESC) and the European Respiratory Society (ERS). Endorsed by: Association for European Paediatric and Congenital Cardiology (AEPC), International Society for Heart and Lung Transplantation (ISHLT). Eur Heart J 2016;37:67-119.

2 Schermuly RT, Ghofrani HA, Wilkins MR, et al. Mechanisms of disease: pulmonary arterial hypertension. Nat Rev Cardiol 2011;8:443-55.

$3 \mathrm{Kim}$ NH, Delcroix M, Jenkins DP, et al. Chronic thromboembolic pulmonary hypertension. J Am Coll Cardiol 2013;62:D92-9.

$4 \mathrm{O}^{\prime}$ Connell C, O'Callaghan DS, Humbert M. Novel medical therapies for pulmonary arterial hypertension. Clin Chest Med 2013;34:867-80.

5 Benza RL, Miller DP, Barst RJ, et al. An evaluation of long-term survival from time of diagnosis in pulmonary arterial hypertension from the REVEAL Registry. Chest 2012;142:448-56.

6 Zhang R, Dai LZ, Xie WP, et al. Survival of Chinese patients with pulmonary arterial hypertension in the modern treatment era. Chest 2011;140:301-9.

7 Zhai Z, Wang J, Zhao L, et al. Pulmonary hypertension in China: pulmonary vascular disease: the global perspective. Chest 2010;137:69S-77S.

8 Gu S, Liu Y, Su PX, et al. Pulmonary endarterectomy for chronic thromboembolic pulmonary hypertension: preliminary exploration in China. Chin Med J 2010;123:979-83.

9 Humbert M. Pulmonary arterial hypertension and chronic thromboembolic pulmonary hypertension: pathophysiology. Eur Respir Rev 2010;19:59-63.

10 Ghofrani HA, Galiè N, Grimminger F, et al. Riociguat for the treatment of pulmonary arterial hypertension. N Engl J Med 2013;369:330-40.

11 Ghofrani HA, D'Armini AM, Grimminger F, et al. Riociguat for the treatment of chronic thromboembolic pulmonary hypertension. N Engl J Med 2013;369:319-29.

12 McGoon MD, Benza RL, Escribano-Subias P, et al. Pulmonary arterial hypertension: epidemiology and registries. J Am Coll Cardiol 2013;62:D51-9.

13 Dong L, He JG, Liu ZH, et al. [Multicenter study of disease attributes in adult patients with pulmonary hypertension]. Zhonghua Yi Xue Za Zhi 2012;92:1087-90.

14 Simonneau G, Barst RJ, Galiè N, et al. Continuous subcutaneous infusion of treprostinil, a prostacyclin analogue, in patients with pulmonary arterial hypertension: a double-blind, randomized, placebo-controlled trial. Am J Respir Crit Care Med 2002;165:800-4.

15 Galiè N, Ghofrani HA, Torbicki A, et al. Sildenafil citrate therapy for pulmonary arterial hypertension. N Engl J Med 2005;353:2148-57.

16 Galiè N, Brundage BH, Ghofrani HA, et al. Tadalafil therapy for pulmonary arterial hypertension. Circulation 2009;119:2894-903.

17 Olschewski H, Simonneau G, Galiè N, et al. Inhaled iloprost for severe pulmonary hypertension. N Engl J Med 2002;347:322-9.

18 Galie N, Olschewski H, Oudiz RJ, et al. Ambrisentan for the treatment of pulmonary arterial hypertension: results of the ambrisentan in pulmonary arterial hypertension, randomized, double-blind, placebo-controlled, multicenter, efficacy (ARIES) study 1 and 2. Circulation 2008;117:3010-19.

19 Rubin LJ, Badesch DB, Barst RJ, et al. Bosentan therapy for pulmonary arterial hypertension. N Engl J Med 2002;346:896-903.

20 Dai $L Z$, Jiang $X$, Wang $Y$, et al. [The efficacy and safety of bosentan therapy for Chinese patients with idiopathic pulmonary arterial hypertension: an open-label, prospective multicenter study]. Zhonghua Xin Xue Guan Bing Za Zhi 2011;39:124-7.

21 Zeng WJ, Xiong CM, Zhao L, et al. Atorvastatin in pulmonary arterial hypertension (APATH) study. Eur Respir J 2012;40:67-74. 


\section{Original research}

22 Chen FD, Zhou DX, Di RM, et al. [Efficacy and safety of ambrisentan therapy in Chinese patients with pulmonary hypertension]. Zhonghua Yi Xue Za Zhi 2013;93:2736-8.

23 Xiong CM, Lu XL, Shan GL, et al. Oral sildenafil therapy for Chinese patients with pulmonary arterial hypertension: a multicenter study. I Clin Pharmacol 2012;52:425-31.

$24 \mathrm{Xu} X \mathrm{X}$, Jing ZC, Zhang JH, et al. The efficacy and safety of sildenafil in Chinese patients with pulmonary arterial hypertension. Hypertens Res 2009:32:911-15.

25 Jing ZC, Strange G, Zhu XY, et al. Efficacy, safety and tolerability of bosentan in Chinese patients with pulmonary arterial hypertension. J Heart Lung Transplant 2010:29:150-6.
26 Gabler NB, French B, Strom BL, et al. Validation of 6-minute walk distance as a surrogate end point in pulmonary arterial hypertension trials. Circulation 2012;126:349-56.

27 Mathai SC, Puhan MA, Lam D, et al. The minimal important difference in the 6-minute walk test for patients with pulmonary arterial hypertension. Am J Respir Crit Care Med 2012;186:428-33.

28 Jaïs $X$, D'Armini AM, Jansa $P$, et al. Bosentan for treatment of inoperable chronic thromboembolic pulmonary hypertension: BENEFiT (Bosentan Effects in iNopErable Forms of chronlc Thromboembolic pulmonary hypertension), a randomized, placebo-controlled trial. J Am Coll Cardiol 2008;52: 2127-34. 